\title{
Thermal decomposition and reaction sintering for synthesis of mullite-zirconia composite using kaolin, $\gamma$-alumina and zirconia
}

\author{
M.A.Aswad ${ }^{1}$, S. H.A.Alfatlawi ${ }^{1}, A . N$. Saud $^{2 *}$ \\ ${ }^{1}$ University of Babylon, Department of Materials Engineering, Babylon, Iraq \\ ${ }^{2}$ Al-Mustaqbal University College, Department of Biomedical Engineering, Babylon, Iraq
}

\begin{abstract}
The refractory materials used in the wall of the furnaces for glass melting can be prepared from mullite-zirconia composite material. The composite of mullite/zirconia was synthesized from Iraqi kaolin, $\gamma$-alumina, and zirconia using thermal decomposition with reaction sintering at $1600{ }^{\circ} \mathrm{C}$. Several batches were prepared with various ratios of kaolin, $\gamma$-alumina, and zirconia, and the composite compositions were selected from the $\mathrm{Al}_{2} \mathrm{O}_{3}-\mathrm{SiO}_{2}-\mathrm{ZrO}_{2}$ phase diagram. The mullite-zirconia composite was prepared with different steps beginning with milling the starting materials, semi-dry uniaxial pressing, and then reactive sintering at various temperatures $\left(1200,1400\right.$, and $\left.1600{ }^{\circ} \mathrm{C}\right)$. The predicted phases $\mathrm{ZrO}_{2}$ and $\mathrm{Al}_{6} \mathrm{Si}_{2} \mathrm{O}_{13}$ were identified by $\mathrm{X}$-ray diffraction patterns according to the phase diagram for all the batches. The lower amount of the zirconia added to mullite reduced porosity and improved the bulk density of the mullite/zirconia composite. The thermal expansion coefficient slightly increased with the addition of zirconia. It also enhanced the thermal shock resistance of the composite. Finally, the mechanical properties were improved by increasing the amount of zirconia particles in a matrix of mullite due to the phase transformation of zirconia from tetragonal to monoclinic phase.
\end{abstract}

Keywords: Iraqi kaolin, gamma-alumina, zirconia, mullite, composite materials, thermal decomposition process, reaction sintering.

\section{INTRODUCTION}

The mullite material can be prepared from an aluminosilicate compound and used in various applications [1]. Mullite- $\mathrm{ZrO}_{2}$ composite materials can be used in different industries, for example, in glass and steel industries due to their suitable physical, thermal, and mechanical properties, and, also, the excellent corrosion resistance against slags due to the high melting temperature of $2715^{\circ} \mathrm{C}[2,3]$. These composite materials possess high fracture toughness, fracture strength, and thermal shock resistance because the zirconia particles distributed homogeneously in the mullite matrix cause improvement of the properties mentioned [4-8].

There are different sources used for the preparation of mullite $\left(\mathrm{Al}_{6} \mathrm{Si}_{2} \mathrm{O}_{13}\right)$; one of the methods is the thermal decomposition of kaolinite at high temperature into oxides and then the transformation of these oxides into mullite [9]. Other methods were used to prepare mullite-zirconia composite material, such as the sol-gel process, and the precursors used in this method were aluminum chloride hexahydrate, pure silica, and pure aluminum, and the sintering was at $1450{ }^{\circ} \mathrm{C}$ for $2 \mathrm{~h}$. The mullite was reinforced by zirconia particles with different contents of 5,10 , and 15 wt $\%$ to improve different properties. The microstructure of the mullite-zirconia composite material was observed with a scanning electron microscope, and the crystalline phases were identified by $\mathrm{X}$-ray diffraction $[10,11]$. Also, the mullite-zirconia composite material was prepared using the

*amir.saud92@gmail.com

Dhttps://orcid.org/0000-0001-6049-387X electrofusion method, and the starting materials were $\mathrm{Al}_{2} \mathrm{O}_{3}$ and $\mathrm{ZrSiO}_{4}$. This process is conducted at high temperature due to the high thermodynamic stability of zirconia for synthesizing the refractory materials $[6,12]$. The chemical reactions for the preparation of mullite-zirconia composite materials are [10]:

$$
\begin{aligned}
& 2 \mathrm{SiO}_{2}+3 \mathrm{Al}_{2} \mathrm{O}_{3} \rightarrow \mathrm{Al}_{6} \mathrm{Si}_{2} \mathrm{O}_{13} \\
& 2 \mathrm{ZrSiO}_{4}+3 \mathrm{Al}_{2} \mathrm{O}_{3} \rightarrow 2 \mathrm{ZrO}_{2}+\mathrm{Al}_{6} \mathrm{Si}_{2} \mathrm{O}_{13} \\
& 4 \mathrm{ZrSiO}_{4}+12 \mathrm{Al}+9 \mathrm{O}_{2} \rightarrow 4 \mathrm{ZrO}_{2}+2 \mathrm{Al}_{6} \mathrm{Si}_{2} \mathrm{O}_{13}
\end{aligned}
$$

The tetragonal zirconia phase was stabilized by using different oxides, for example, ceria, magnesia, and yttria, to prepare the partially stabilized zirconia. The properties of the mullite-zirconia improved due to the phase transformation of $\mathrm{ZrO}_{2}$ from tetragonal to monoclinic phase that causes volume change in the zirconia particles stopping the crack propagation in the mullite matrix [13]. In the current research, the kaolin was used as the starting material for the synthesis of mullite material due to the economic cost caused by the reduction of the sintering temperature. The loss of ignition of the kaolin can limit the densification of mullite due to the gas releasing during the reaction sintering. The objective of the present work is focused on the development of a new process of synthesis of a low-cost mullite-zirconia composite of high quality and performance using Iraqi kaolin, $\gamma$-alumina, and zirconia as starting materials. The effect of reaction sintering temperature on the mullite properties was studied. Then, the effect of the zirconia content of the mullite-based composite was investigated on the physical, thermal, and mechanical properties. 


\section{MATERIALS AND METHODS}

Starting materials: kaolin located in the Western part of Iraq as a source for both alumina and silica, $\gamma-\mathrm{Al}_{2} \mathrm{O}_{3}$, and $\mathrm{ZrO}_{2}$ powders were used for the preparation of zirconiamullite composite (Table I). The chemical composition of Iraqi kaolin is shown in Table II, and the particle size distribution curves of the starting materials are shown in Fig. 1. The starting materials and mullite/zirconia composite were characterized by X-ray diffraction (XRD) using a diffractometer (Shimadzu, 6000) at room temperature using $\mathrm{CuK} \alpha$ radiation $\left(\lambda=1.5405 \AA\right.$ ), a scanning speed of $6^{\circ} / \mathrm{min}$ from $10^{\circ}$ to $80^{\circ}$ of $2 \theta$, and applied power of $40 \mathrm{kV} / 30 \mathrm{~mA}$. XRD patterns of the starting materials (Fig. 2) were in agreement with the JCPDS files 29-0063, 29-1490, and 410017 for $\gamma-\mathrm{Al}_{2} \mathrm{O}_{3}$, Iraqi kaolin, and zirconia, respectively.

Table I - Starting materials used for the synthesis of mullitezirconia composite.

\begin{tabular}{llcc}
\hline Material & Source & $\begin{array}{c}\text { Purity } \\
(\%)\end{array}$ & $\begin{array}{c}\text { Particle } \\
\text { size }(\mu \mathrm{m})\end{array}$ \\
\hline Kaolin & Western Iraq & 98.0 & 6.25 \\
Zirconia & Shanghai Zhenxin & 99.9 & 2.81 \\
& Reag. Fact. & & \\
$\boldsymbol{\gamma}-\mathrm{Al}_{2} \mathrm{O}_{3}$ & Shanghai Zhenxin & 99.9 & 90.21 \\
& Reag. Fact. & & \\
\hline
\end{tabular}

Table II - Chemical composition (mass \%) of Iraqi kaolin.

\begin{tabular}{lcccccc}
\hline $\mathrm{SiO}_{2}$ & $\mathrm{Al}_{2} \mathrm{O}_{3}$ & $\mathrm{Fe}_{2} \mathrm{O}_{3}$ & $\mathrm{MgO}$ & $\mathrm{Na}_{2} \mathrm{O}$ & $\mathrm{K}_{2} \mathrm{O}$ & LOI $^{*}$ \\
\hline 51.89 & 32.41 & 1.43 & 0.30 & 0.29 & 0.34 & 13.27 \\
\hline *- loss on ignition. & & & & &
\end{tabular}

Preparation of mullite-zirconia composite samples: the average particle size of $\gamma$-alumina was high when compared to other starting materials (kaolin and zirconia), as shown in Fig. 1. The $\gamma$-alumina was milled and homogenized by planetary milling for $8 \mathrm{~h}$ to increase the surface area. The milling process was done using corundum balls and distilled water as a medium, and then the $\gamma$-alumina powder was dried in an oven at $110{ }^{\circ} \mathrm{C}$ for $8 \mathrm{~h} \mathrm{[14].} \mathrm{The} \mathrm{size} \mathrm{distribution}$ of alumina particles was analyzed using a laser particle size analyzer (Bettersize 2000, Yima), as this device can analyze the particle size in the range from 0.02 to $2000 \mu \mathrm{m}$ with an accuracy of $1 \%$ (CRM D50). The average particle size of milled $\gamma$-alumina was $4.54 \mu \mathrm{m}$ (Table III), and the cumulative and differential particle size distribution curves of milled $\gamma$-alumina is shown in Fig. 3. The Iraqi kaolin and $\gamma$-alumina for preparation of mullite were dried in an oven for $24 \mathrm{~h}$ to release the content of moisture and increase the efficiency of the starting materials. The relative amounts of the kaolin and $\gamma$-alumina were $3: 2$, and on this mixing ratio, various contents of zirconia $(3,5$, and $10 \mathrm{wt} \%)$ were added. The starting materials were mixed in a blender for 6 $\mathrm{h}$ after adding PVA for obtaining the optimum homogeneous
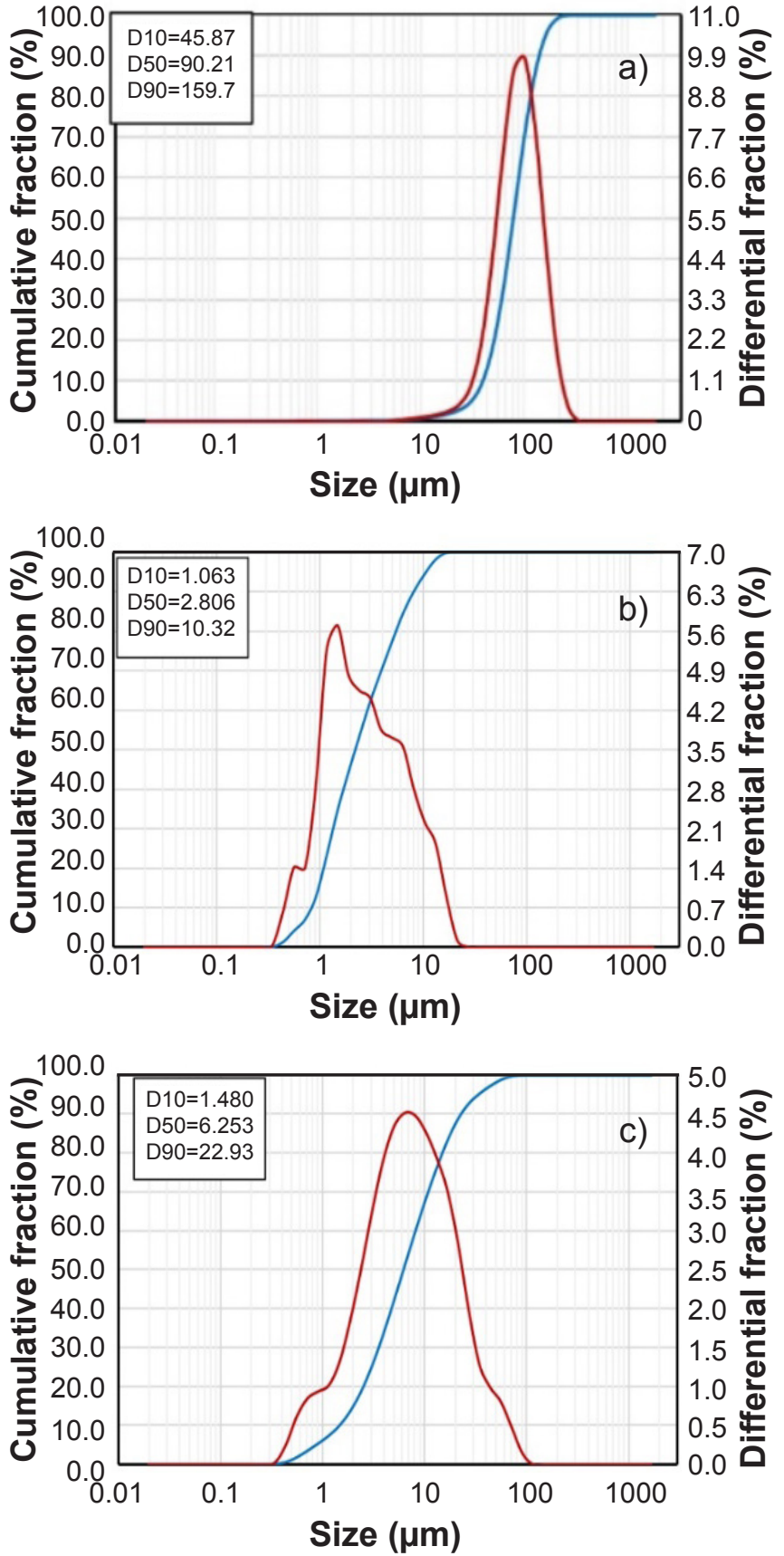

Figure 1: Cumulative and differential particle size distribution curves of the starting materials: a) $\gamma-\mathrm{Al}_{2} \mathrm{O}_{3}$; b) zirconia; and c) Iraqi kaolin.

batches. The mixed powder of the starting materials was formed in a stainless steel mold by semi-dry pressing using a uniaxial pressure device at different loads $(70,111$, and 159 $\mathrm{MPa}$ ) with a holding time of $2 \mathrm{~min}$. Steel die had a diameter and height of 20 and $70 \mathrm{~mm}$, respectively. The formed sample with disc shape was removed from the mold and dried in an oven at $110{ }^{\circ} \mathrm{C}$ for $24 \mathrm{~h}$. Then the composite samples were sintered at different temperatures $\left(1200-1600{ }^{\circ} \mathrm{C}\right)$.

Characterization of mullite- $\mathrm{ZrO}_{2}$ samples. Physical properties: the shrinkage of mullite and mullite-zirconia composite was due to the sintering temperature, which was measured according to the American Society for Testing and 


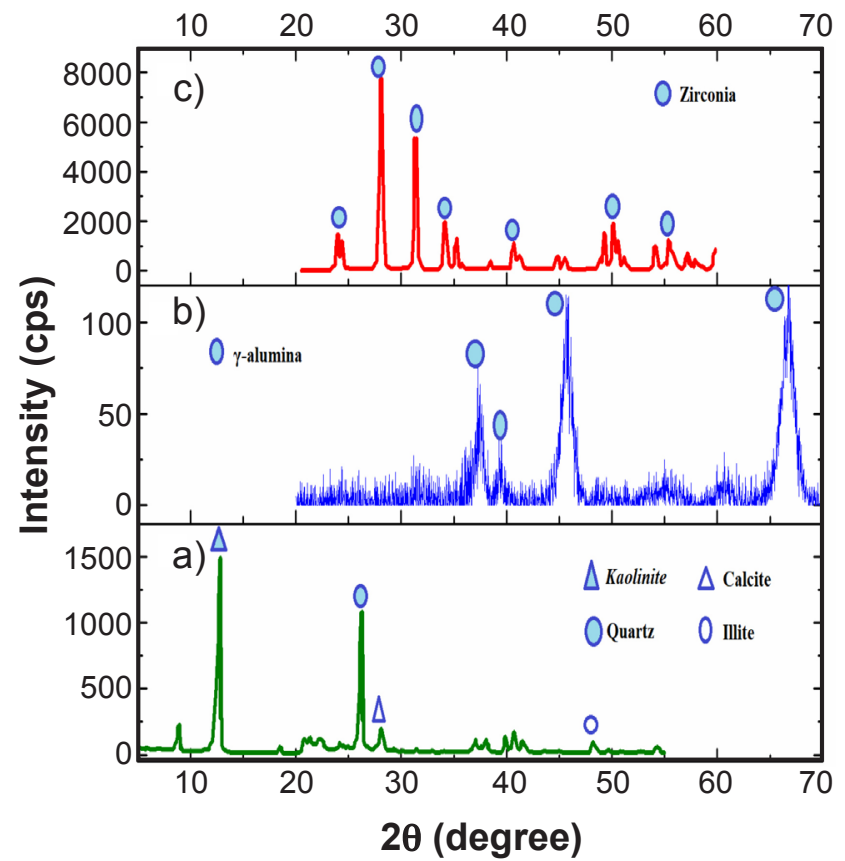

Figure 2: X-ray diffraction patterns of the starting materials for the synthesis of mullite-zirconia: a) Iraqi kaolin; b) $\gamma$-alumina; and c) zirconia.

Table III - Average particle size of $\gamma$-alumina before and after milling.

\begin{tabular}{cc}
\hline Before milling & After milling \\
\hline $90.21 \mu \mathrm{m}$ & $4.54 \mu \mathrm{m}$ \\
\hline
\end{tabular}

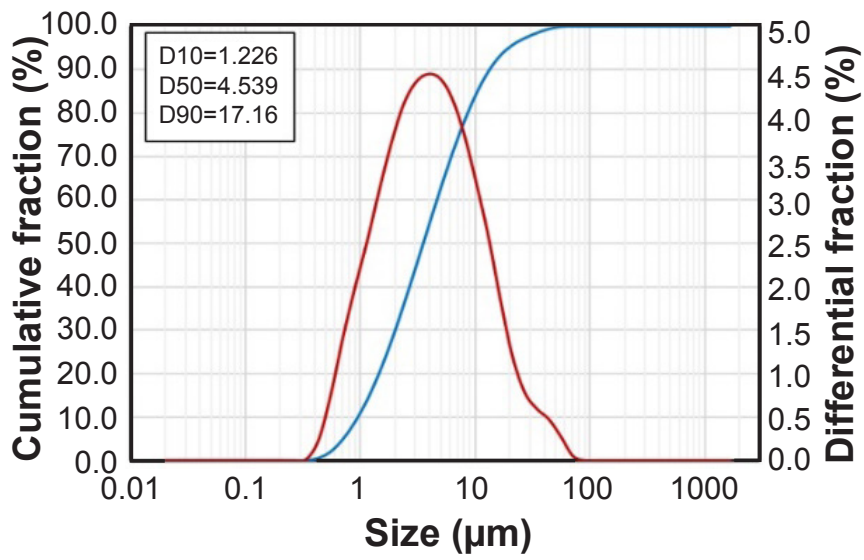

Figure 3: Cumulative and differential particle size distribution curves of $\gamma$-alumina after milling.

Materials (ASTM). The porosity has a significant impact on the final properties of the sintered mullite and mullitezirconia composite. Prepared sintered samples showed porous bodies, where the porosity was a measure of the open and closed pores. The amount of water absorbed by the body is a function of the open porosity. The water absorption represents the relationship between the mass of water absorbed in the pores to the mass of the solid part of the body. ASTM standard (C373-88) was used for measuring the bulk density, apparent porosity, and water absorption of the prepared samples; for each sample, three specimens were measured using a digital hydrostatic balance (DSJ5). The samples were dried in an oven at $110{ }^{\circ} \mathrm{C}$ for $24 \mathrm{~h}$ and then allowed for cooling down to room temperature; then, the dry weight of the mullite and mullite-zirconia samples was measured. Thermal properties: the coefficient of thermal expansion represents the relationship between the variation of the sample length in a temperature range. The mullite-zirconia composite was formed as a rectangular sample with a length of $50 \mathrm{~mm}$. The samples were tested in a dilatometer using a $\mathrm{SiO}_{2}$ push rod. The samples were heated at a constant heating rate between 50 and $800{ }^{\circ} \mathrm{C}$ for measuring the thermal expansion coefficient $(\alpha)$ by:

$$
\frac{\Delta \mathrm{L}}{\mathrm{L}}=\alpha \cdot \Delta \mathrm{T}
$$

where $\mathrm{L}$ is the original length, $\Delta \mathrm{L}$ the change of length, and $\Delta \mathrm{T}$ the range of temperature. The mullite- $\mathrm{ZrO}_{2}$ composite samples were cooled from high to room temperature in a short time, and the failure occurred due to the thermal stresses caused by the temperature gradient in the sample. Thermal shock resistance was measured by heating the sample in an electric furnace at different temperatures $\left(200,400\right.$, and $\left.600{ }^{\circ} \mathrm{C}\right)$ with a soaking time of $1 \mathrm{~h}$. Then the samples were quenched in water for measuring the thermal shock resistance of the sample. Mechanical properties: Vickers hardness was measured by applying a load of $4.9 \mathrm{~N}$ with a holding time of $15 \mathrm{~s}$ using a micro-Vickers hardness tester (TH-717) according to ASTM 1327 standard. The Vickers hardness (HV) value was calculated by:

$$
\mathrm{HV}=1.8544 .\left(\mathrm{P} / \mathrm{d}^{2}{ }_{\text {ave }}\right)
$$

where $\mathrm{P}$ is the applied load $(\mathrm{N})$, and $\mathrm{d}_{\text {ave }}$ is the average of the two impression diagonals $\left(\mathrm{d}_{1}\right.$ and $\left.\mathrm{d}_{2}, \mathrm{~mm}\right)$. The mullitezirconia composite samples were prepared as discs with dimensions of $\phi 20 \times 20 \mathrm{~mm}$ for compressive strength according to ASTM C773-88 standard. The compressive strength $(\sigma)$ was calculated with the maximum applied force (F) divided by the cross-sectional area of the sample (A) by:

$$
\sigma=F / A
$$

\section{RESULTS AND DISCUSSION}

$X$-ray diffraction: Fig. 4a shows the X-ray diffraction pattern of the mullite prepared at $1600{ }^{\circ} \mathrm{C}$ from starting materials ( $\gamma$-alumina and Iraqi kaolin) as a matrix to prepare the mullite-zirconia composite material. Fig. $4 \mathrm{~b}$ shows the XRD pattern of the mullite-zirconia composite material. The XRD patterns showed good agreement with JCPDS files 15-0776 and 41-0017 for mullite and zirconia phases, respectively.

Physical properties: the results of firing shrinkage, porosity, and bulk density of mullite are shown in Fig. 5. The increase in sintering temperature from 1200 to $1600^{\circ} \mathrm{C}$ caused an increase in the bulk density and a decrease in porosity, and 


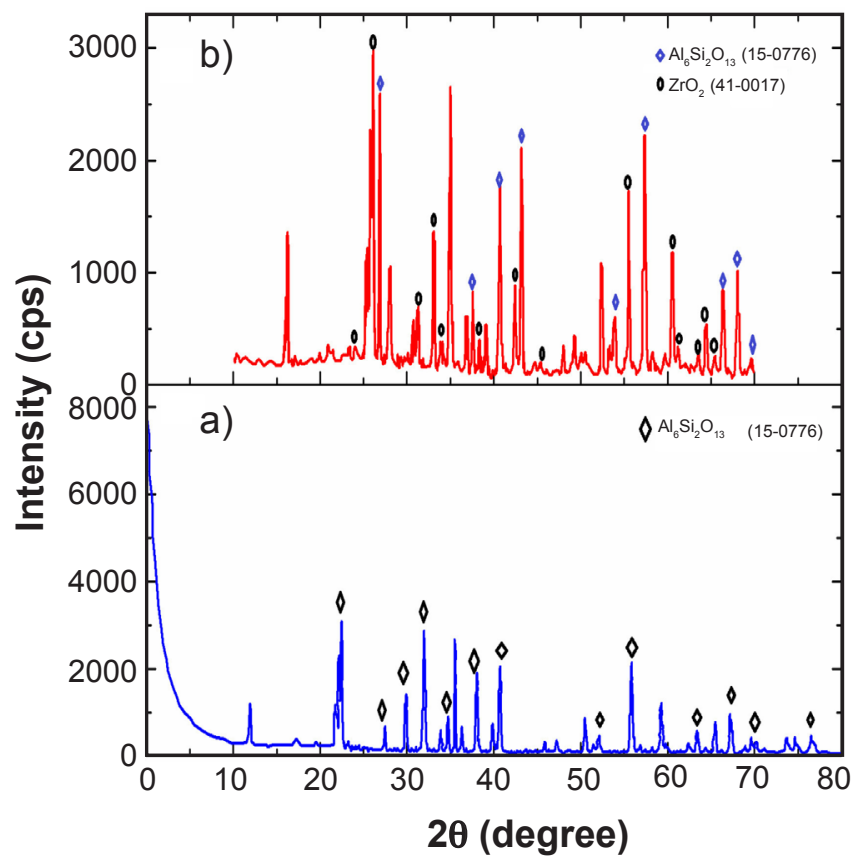

Figure 4: X-ray diffraction patterns of mullite (a), and mullitezirconia (b) sintered at $1600{ }^{\circ} \mathrm{C}$.

the silica-rich glassy phase with high viscosity was suitable to precipitate the mullite $[15,16]$. The compounds of aluminasilica at a temperature above $1400{ }^{\circ} \mathrm{C}$ led to the formation of the mullite compound and change in the density of mullite. Fig. $6 \mathrm{~b}$ shows the porosity of the mullite-zirconia composite material because the kaolin material possessed high porosity compared with the alumina. The calculated porosity values of the mullite were in the range between $15 \%$ and $70 \%$. The increase of the body shrinkage meant that the pore size was reduced in the mullite sample. The apparent porosity of mullite was $21 \%$, and the water absorption was $10.4 \%$.

Fig. 6 shows the physical properties of mullite-zirconia composite with different content of zirconia. An increase in the value of firing shrinkage, as shown in Fig. 6a when the $\mathrm{ZrO}_{2}$ content was $10 \%$, can be interpreted based on the fact that at this content, the better grain distribution allowed the largest area of contact between the grains (i.e., high surface area). The firing shrinking of the mullite-zirconia with 5\% $\mathrm{ZrO}_{2}$ had a slight reduction in sample dimensions due to the increase of the grain size of the compacted sample and the decrease of the contact area between the grains. The increase in firing shrinkage refers to a more efficient firing process due to a homogenous grain distribution and an increase of the contact area between the grains. Moreover, the high rate of contraction affects other properties such as the thermal expansion and thermal shock resistance of the mullitezirconia composite sample [17]. The decrease of porosity with the increase of the $\mathrm{ZrO}_{2}$ content is shown in Fig. $6 \mathrm{~b}$. This process increases the efficiency of new composites in applications to obtain a material with physical properties for porous ceramics membrane application. The apparent porosity of the composite material was $10 \%$, the water absorption was $3.7 \%$, and the lowest absorption was with the
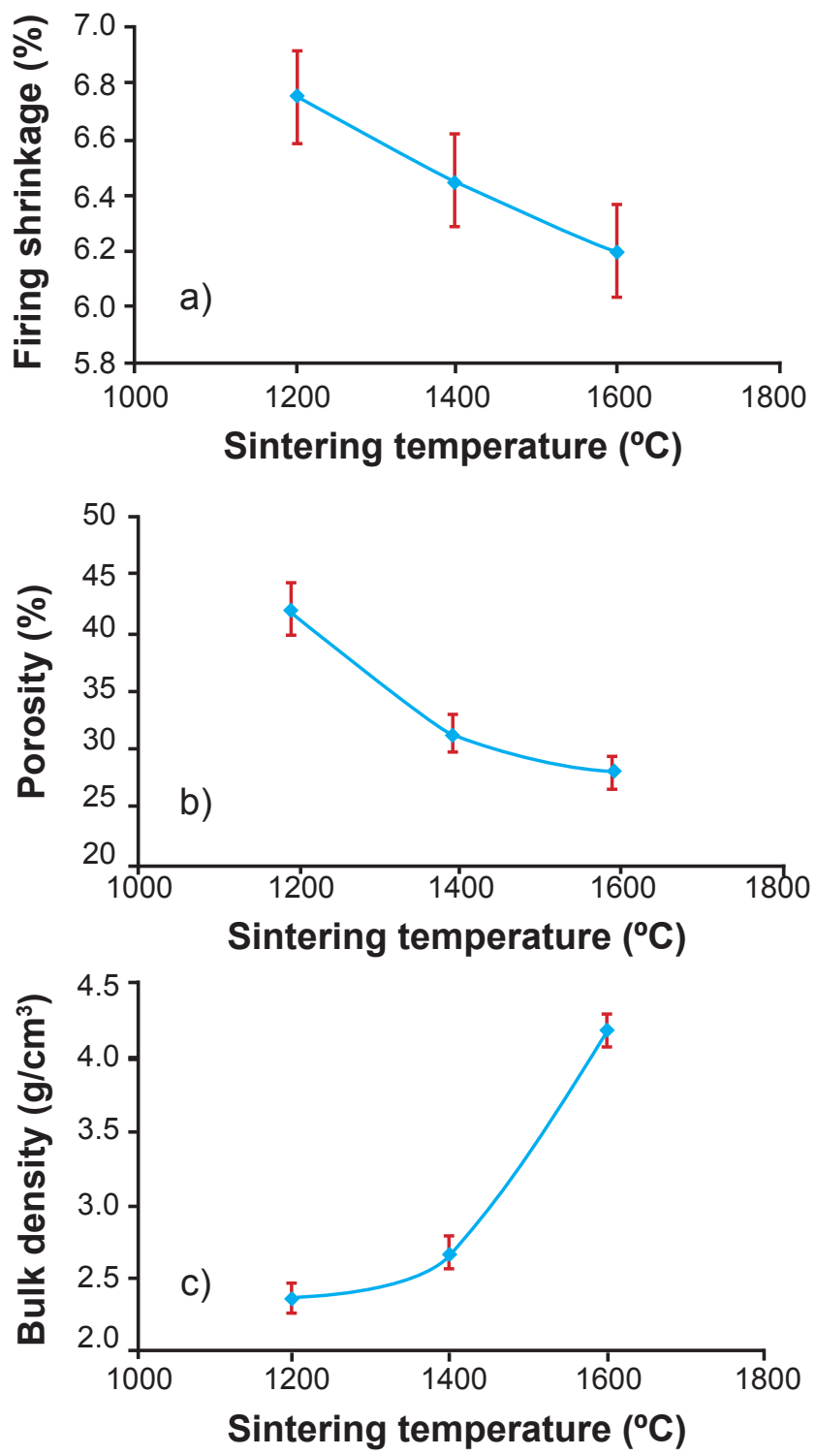

Figure 5: Physical properties of pure mullite as a function of sintering temperature: a) firing shrinkage; b) porosity, and c) bulk density.

addition of $10 \% \mathrm{ZrO}_{2}$. Fig. 6c shows an increase in the value of bulk density with the addition of $10 \% \mathrm{ZrO}_{2}$ in relation to pure mullite $\left(4.18 \mathrm{~g} / \mathrm{cm}^{3}\right)$. The bulk density of the mullitezirconia composite increased with the increase of zirconia content to about $5.7 \mathrm{~g} / \mathrm{cm}^{3}$; at the same conditions of the pure mullite $\left(10 \% \mathrm{ZrO}_{2}\right.$ and a compressive load of $\left.50 \mathrm{kN}\right)$, the increase in the bulk density enhanced the densification of grains and reduced the porosity.

Mechanical properties: the Vickers hardness of the mullite-zirconia composite varied with the zirconia content (Fig. 7) due to the variation in porosity. The Vickers hardness of mullite was $20.9 \mathrm{GPa}$ due to the homogeneous grain size distribution. The hardness achieved the highest value with $3 \%$ zirconia (40.3 GPa) due to zirconia playing a significant role in the toughening of the mullite-zirconia composite by phase transformation in the partially stabilized zirconia from 

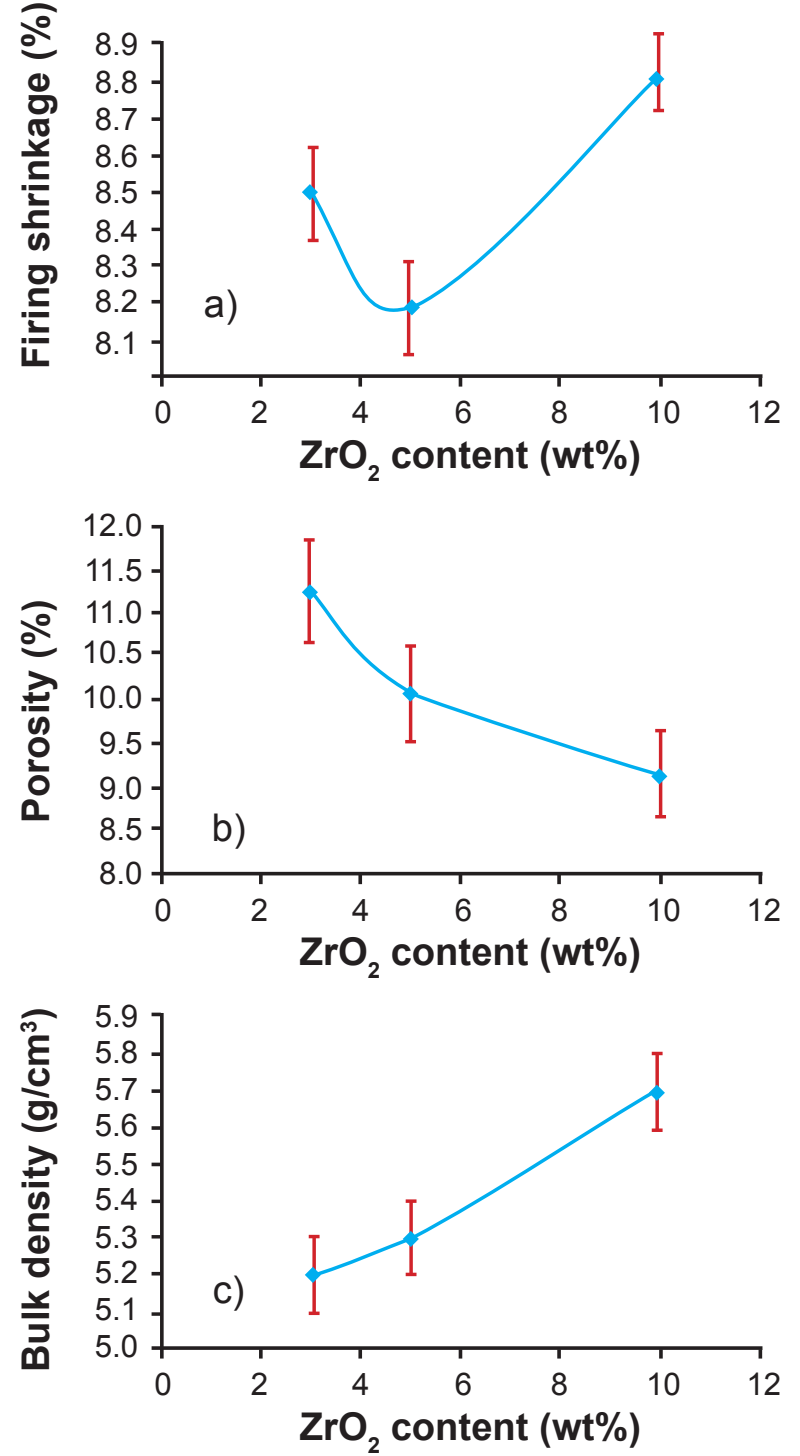

Figure 6: Physical properties of mullite-zirconia composite sintered at $1600{ }^{\circ} \mathrm{C}$ as a function of zirconia content: a) firing shrinkage; b) porosity; and c) bulk density.

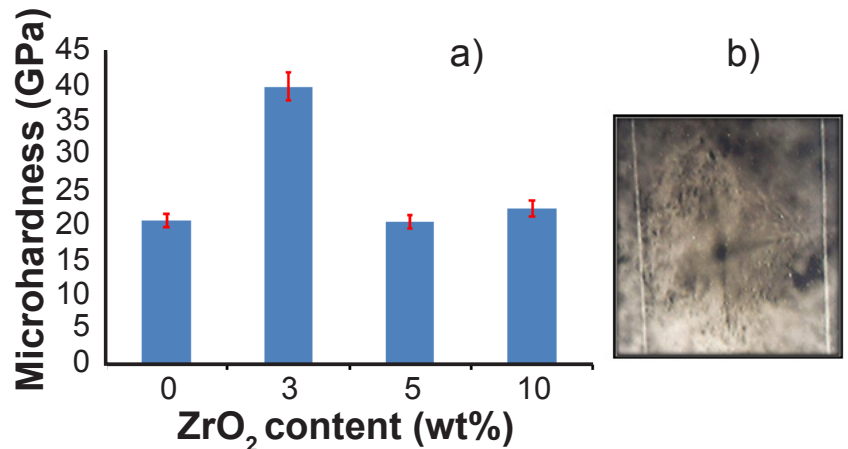

Figure 7: Microhardness measurements of the mullite-zirconia composite with different content of zirconia (a), and a micrograph showing a Vickers indentation at an applied load of $4.9 \mathrm{~N}$ and holding time of $15 \mathrm{~s}$ (b).

tetragonal to monoclinic phase that caused a change in volume in the zirconia grain. Densification was improved by increasing the sintering temperature, and compaction was enhanced by increasing the amount of zirconia. The decrease in the hardness value with zirconia additions above $3 \%$ appears to be due to the increase in porosity, or the hardness values were measured in regions containing pores. In general, the hardness of mullite-composite materials was affected by the crystal size, porosity, and microstructure of mullite-zirconia composite [18].

The compressive strength values of the mullitezirconia composite are shown in Fig. 8. The results of the compressive strength of the composite material increased with the increase of the amount of the zirconia that enhanced the densification since the kaolin had a loss on ignition that caused the gas generation during reaction sintering. The densification process of the mullite-zirconia occurred in three stages: re-arrangement of the grains, sintering of the solid solution, and solutionprecipitation. For the same reason mentioned above, the toughening mechanism of the martensitic transformation of the zirconia led to the improvement of the compressive strength of mullite-zirconia composite [13-16].

Thermal properties: the relationship between the thermal expansion coefficients of mullite and mullite-zirconia composite

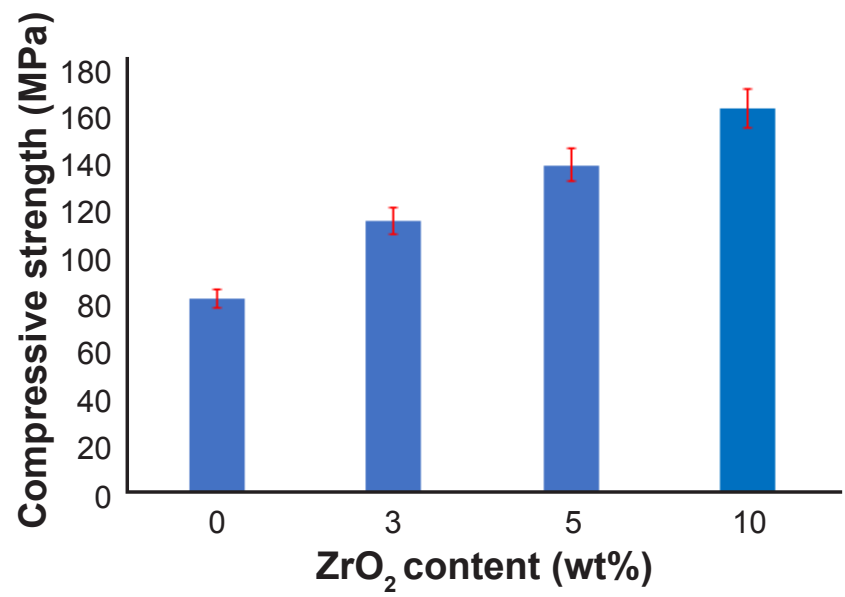

Figure 8: Results of the compressive strength of the mullitezirconia composite with various zirconia contents.

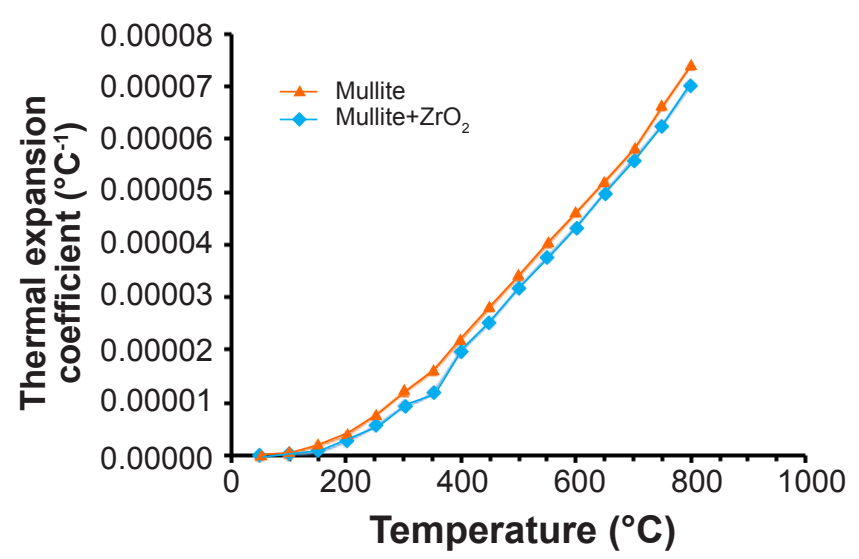

Figure 9: Thermal expansion coefficient versus temperature of mullite and mullite-zirconia. 
is shown in Fig. 9. The volume of the composite material increased in small increments when the sample was heated. The thermal expansion coefficient (TEC) is significant for using mullite-zirconia composite in high-temperature applications for an increase in its lifetime. TEC of the pure mullite was low, so the effect of $\mathrm{ZrO}_{2}$ content led to a slight increase of this coefficient for the mullite- $\mathrm{ZrO}_{2}$ composite. The TEC of mullite-zirconia increased in a small amount with increasing temperature, possibly due to the increase of the densification of composite material and the phase transformation behavior of the partially stabilized zirconia from tetragonal to monoclinic phase [13, 19].

The mullite-zirconia composite contained an amount of glassy $\mathrm{SiO}_{2}$ phase that led to the development of the mullite
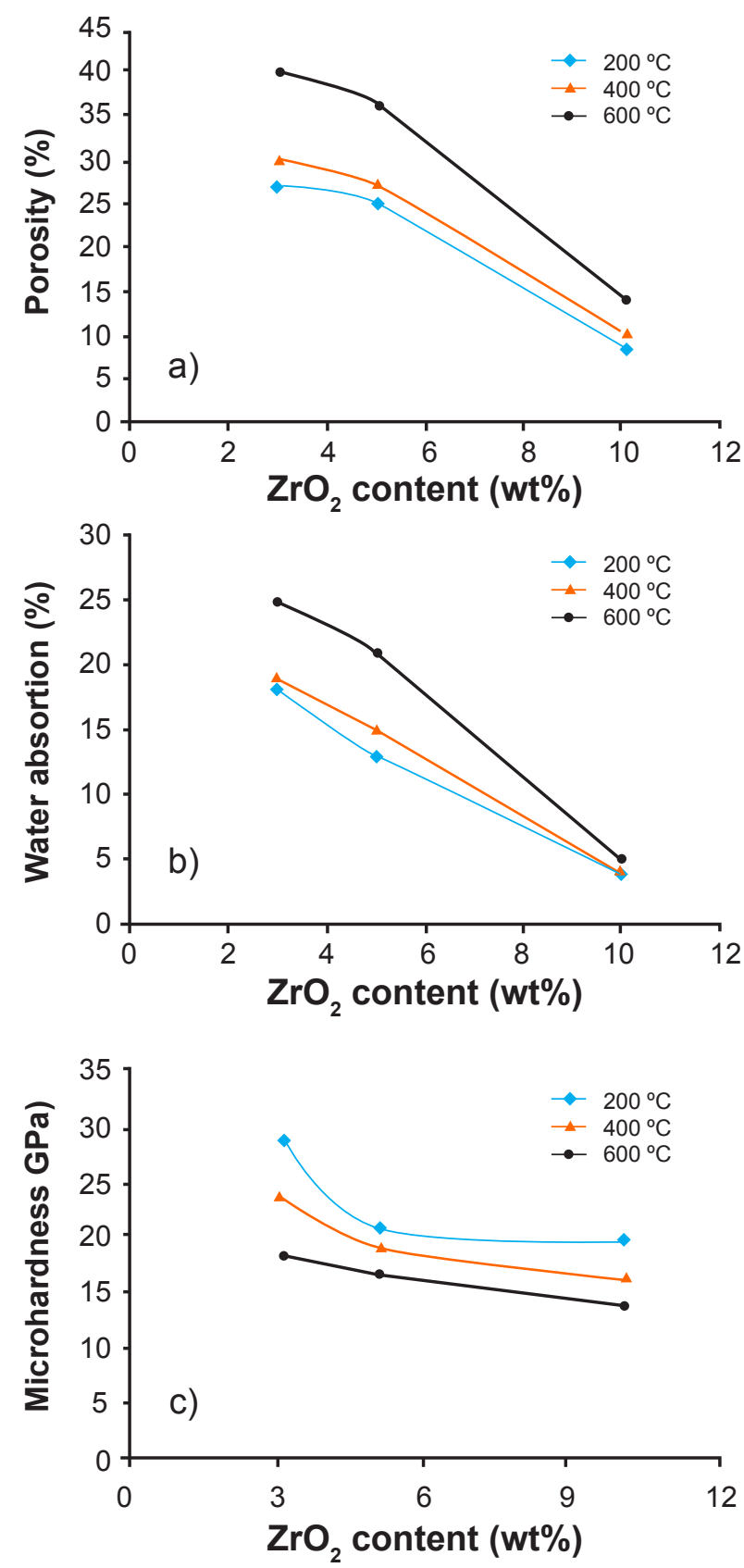

Figure 10: Effects of thermal shock on the porosity (a), water absorption (b), and microhardness (c) of the mullite with different content of zirconia. bridge. The reinforcement of mullite by zirconia particles stoped the microcracks development during the thermal shock, and the glassy silica phase caused a critical role to fill the pores in mullitezirconia composite and make it denser [6-16]. The thermal stresses generated in the mullite-zirconia composite due to the sudden change in temperature from high to room temperature caused microcracking of the material. The failure happens when the material strength does not withstand the thermal stresses. The thermal shock process caused the deterioration of the physical properties and microhardness of the mullite-zirconia composite, as shown in Fig. 10. The mullite-zirconia composite withstands against the thermal shock due to the high thermal stability of the composite and low thermal expansion coefficient [16]. Previous studies have mentioned that the mullite- $\mathrm{ZrO}_{2}$ composite with good densification improves the thermal shock resistance [20].

\section{CONCLUSIONS}

Pure mullite material was synthesized from Iraqi kaolin and $\gamma$-alumina using thermal decomposition and reaction sintering. Then the mullite was reinforced by zirconia particle for improving the physical, mechanical, and thermal properties. The bulk density was enhanced by increasing the content of zirconia; the glassy silica phase filled the pores and increased the densification of the composite materials that reduced the composite porosity. The zirconia particles improved the mechanical properties due to the phase transformation of the partially stabilized zirconia. The microhardness decreased with the increase of zirconia from 3 to $10 \mathrm{wt} \%$; the hardness values were 40.3 and $22.7 \mathrm{GPa}$, respectively. The increase of the zirconia content from 3 to 10 wt $\%$ caused the increase of the compressive strength from 83.2 to $163.2 \mathrm{MPa}$. Also, the increase in temperature from 50 to $800{ }^{\circ} \mathrm{C}$ led to an increase in the thermal expansion coefficient of mullite-zirconia composite up to $0.000074{ }^{\circ} \mathrm{C}^{-1}$. Finally, the physical and mechanical properties deteriorated during the thermal shock when the temperature difference was increased from 200 to $600{ }^{\circ} \mathrm{C}$.

\section{REFERENCES}

[1] J. Anggono, J. Teknik Mesin 7, 1 (2005) 1.

[2] Th. Chotard, L.A. Morales, M. Laure, J.Poirier, Ceramics 2,2 (2019) 587.

[3] M.L. Bouchetou, J. Poirier, O. Joubert, M.A. Weissenbacher, in Proc. $60^{\text {th }}$ Int. Colloq. Refract., Aachen (2017) 162.

[4] X. Xu, J. Li, J. Wu, Z. Tang, L. Chen, Y. Li, C. Lu, Ceram. Int. 43 (2017) 1762.

[5] M.L. Bouchetou, J. Poirier, L.A. Morales, T. Chotard, O. Joubert, M. Weissenbacher, Ceram. Int. 45 (2019) 12832.

[6] H. Pooladvand, B. Mirhadi, S. Baghshahi, A.R. Souri, K. Arzani, Adv. Appl. Ceram. 108 (2009) 389.

[7] T. Walaan, B. Psiuka, J. Kubackib, K. Steca, J. Podwórnya, Ceram. Int. 40 (2014) 5129.

[8] N.M. Rendtorff, L.B. Garrido, E.F. Aglietti, Mater. Sci. Eng. A 498 (2008) 208.

[9] S. Lee, Y.J. Kim, H. Moon, J. Am. Ceram. Soc. 82, 10 
(2004) 2841.

[10] M. Aswad, M.M. Shukur, D.A. Yaseen, J. Univ. Babylon Eng. Sci. 25 (2014) 547.

[11] S. Maitra, A. Rahaman, A. Sarkar, A. Tarafdar, Ceram. Int. 32, 2 (2006) 201.

[12] B. Ma, Y. Li., S. Cui, Y. Zhai, Trans. Nonferrous Met. Soc. China 20 (2010) 2331.

[13] T. Koyama, S. Hayashi, Xasumori, K. Okada, J. Eur. Ceram. Soc. 16 (1996) 231.

[14] A.N. Saud, M.A. Aswad, M.A.A. Al-Dujaili, J. Eng. Appl. Sci. 13, 22 (2018) 9558.
[15] H. Aydin, G. Tokatas, J. Ceram. Proces. Res. 20, 3 (2019) 250

[16] J. Wu, C. Lu, X. Xu, Y. Zhang, J. Wuhan Univ. Technol. Mat. Sci. Edit. 34 (2019) 1062.

[17] M.F. Hernández, P.V. López, A. Violini, G. Suárez, M.S. Conconi, N.M. Rendtorff, Sci. Sinter. 51 (2019) 51.

[18] J. Xiao, W. Chen, L. Wei, W. He, H. Guo, Materials 13 (2020) 671.

[19] F. Sahnoune, N. Saheb, EPJ Web Conf. 6 (2010) 20005. [20] H. Aydın, Iran. J. Mater. Sci. Eng. 16 (2019) 4. (Rec.01/05/2020, Rev. 14/06/2020, Ac. 22/07/2020) 